\title{
DETECCIÓN DE ANTICUERPOS Y ANTÍGENOS PARA EL DIAGNÓSTICO DE Fasciola hepatica EN ALPACAS NATURALMENTE INFECTADAS
}

\author{
Olga Li E. ${ }^{1}$, Guillermo Leguía P. ${ }^{2}$, Ana Espino M. ${ }^{3}$, Blanca Duménigo R. ${ }^{3}$, \\ Ailén Díaz E. ${ }^{3}$ y Oscar Otero ${ }^{3}$
}

\section{Abstract}

The aim of this study was to standardize the indirect ELISA test for the detection of antibodies and to evaluate a coproantigen detection test (ES-78 sandwich ELISA) for the Fasciola hepatica diagnoses in alpacas. For the indirect ELISA, the excretion-secretion products (ES) were used as antigens and a peroxidasa anti IgG immunoconjugate of alpaca was obtained through protein A affinity cromatography. The detection ELISA was tested with the FASCIDIG diagnostic kit, which detects metabolics antigens using an AcM-ES78 monoclonal antibody of the IgG 2a sub class. Optical Density (OD) values between 0.075 and 1.435 were obtained using the indirect ELISA, where the cut-off point was 0.226 . The positive control group animals were positive to the test with values between 0.331 and 1.435 . The negative control group animals were negative to the test with values between 0.075 and 0.226 . OD values between 0.060 and 1.532 were obtained using the coproantigen detection ELISA, where the cut-off point was 0.240 . The positive control group animals were positive to the test with OD values between 0.244 and 1.532 and the negative control group animals were negative to the test with values between 0.060 and 0.240 . The sensitivity, specificity and positive and negative predictive values were $100 \%$ for both ELISA tests. Both test can replace the coproparasitologic test. They are suitable for individual diagnosis and for herd diagnosis infections with $F$. hepatica. The indirect ELISA has demonstrated to be a useful and sensitive tool for the pasive fasciolosis diagnosis in alpacas. The coproantigen detection ELISA is a simple, fast and efficient method in the detection of active $F$. hepaticainfection. Both diagnostic methods would be the most suitables techniques for sero-epidemiologic surveys in large herds under intensive grazing systems.

Key words: ELISA, Fasciola hepatica, alpaca

\section{RESUMEN}

El propósito de este trabajo fue estandarizar la prueba de ELISA indirecta para la detec ción de anticuerpos y evaluar una prueba inmunoenzimática de detección de coproantígenos (ES-78 sandwich ELISA) para el diagnóstico de Fasciola hepatica en alpacas. En la prueba de ELISA indirecta se emplearon los productos de excreción y secreción (ES) como antígenos y se obtuvo un inmunoconjugado de peroxidasa anti-IgG

${ }^{1}$ Laboratorio de Patología Clínica, FMV-UNMSM. E-mail: olgalie@ hotmail.com

${ }^{2}$ Facultad de Veterinaria y Zootecnia, Universidad Peruana Cayetano Heredia

${ }^{3}$ Instituto Pedro Kouri, La Habana, Cuba 
de alpacas por cromatografía de afinidad a proteína A. La prueba de ensayo inmunoenzimática de detección fue evaluada mediante el kit de diagnóstico FASCIDIG, el cual detecta antígenos metabólicos usando el anticuerpo monoclonal AcM-ES78 de la subclase IgG 2a. En el ELISA Indirecto se obtuvieron valores de densidad óptica (DO) entre 0.075 a 1.435 donde el punto de corte fue de 0.226 . Los animales del grupo control positivo fueron positivos a la prueba con valores entre 0.331 y 1.435 . Los animales del grupo control negativo resultaron negativos a la prueba con valores de 0.075 a 0.226 . En el ELISA para coproantígenos se obtuvieron valores de DO entre 0.060 y 1.532 , donde el punto de corte fue de 0.240. Los animales del grupo control positivo resultaron positivos con valores de DO de 0.244 a 1.532 y los animales del grupo control negativo resultaron negativos a la prueba con valores entre 0.060 a 0.240 . Los valores de sensibilidad, especificidad y valores predictivos positivo y negativo fueron del $100 \%$ para las dos pruebas de ELISA. Ambas pruebas pueden sustituir al examen coproparasitológico, tanto en el diagnóstico individual, como en rebaños con infección por $F$. hepatica. El ELISA indirecto demostró ser un método sensible y útil para el diagnóstico de fasciolosis pasiva en alpacas. El ELISA para la detección de coproantígenos es un método simple, rápido y eficaz en la detección de infección activa por $F$. hepatica. Ambos métodos de diagnósticos resultan ser técnica de elección para estudios seroepidemiológicos en rebaños de gran número de animales sometidos a pastoreo intenso.

Palabras clave: ELISA, Fasciola hepatica, alpacas

\section{INTRODUCCIÓN}

La fasciolosis en el Perú es una enfermedad endémica en la ganadería, y responsable de cuantiosas pérdidas en la industria pecuaria. Además, puede afectar al hombre y es considerada como una enfermedad zoonótica de importancia en la salud pública (Ministerio de Salud Pública, 1991/1995).

El diagnóstico eficaz de la fasciolosis está basado en el hallazgo de los huevos del parásito en las heces o en el fluido duodenal del individuo parasitado; sin embargo, este diagnóstico no puede realizarse durante la fase aguda de la enfermedad debido a que el parásito se encuentra migrando por el parénquima hepático sin haber llegado a la madurez sexual.

La detección de antígenos parasitarios pertenece a un concepto diagnóstico moderno que, a diferencia de la detección de anticuerpos, permite diagnosticar la infección activa (Langley y Hillyer, 1989). El ensayo inmunoenzimático sobre fase sólida (ELISA) en sus dos variantes más conocidas, el DOT-
ELISA y el FAST-ELISA ha sido en los últimos 10 años la técnica de mayor uso por su elevada sensibilidad, versatilidad y posibilidad de analizar grandes cantidades de muestras, lo cual facilita la realización de estudios epidemiológicos, así como el diagnóstico de casos individuales de fasciolosis (Hillyer et al., 1992).

Los tipos de antígenos mayormente utilizados en el diagnóstico de la fasciolosis han sido los somáticos y los de tegumento. Los antígenos somáticos son aquellos asociados con los tejidos del parásito, y su obtención se logra generalmente por fragmentación y homogenización de los parásitos completos (Espino et al., 1987). Los antígenos tegumentarios son más simples y su composición antigénica está asociada a las moléculas que componen el glicocálix del parásito. Los antígenos tegumentarios, y en menor medida los somáticos, poseen ciertos componentes de reacción cruzada. Es así que diversos investigadores han purificado los antígenos somáticos y tegumentarios para obtener las fracciones más específicas a fin de darles una aplicación diagnóstica. 
Los otros antígenos que forman parte del mosaico antigénico de $F$. hepatica son los productos de excreción-secreción. Estos antígenos no son otros que los productos metabólicos que libera el parásito al medio circundante. Para su obtención se utilizan técnicas de mantenimiento in vitro, mediante las cuales el parásito sobrevive por varios días en un medio libre de suplementos proteicos (Lehner y Sewell, 1980). Estudios comparativos realizados sobre la caracterización inmunológica de este tipo de antígenos revelan que son mucho más simples, inmunogénicos y específicos que los extractos somáticos y tegumentarios (Espino et al., 1993). Han sido correlacionados con los de diferentes tipos de glándulas secretorias del tegumento del parásito en diferentes estadios de desarrollo, denominadas glándulas T0, T1 y T2 (Hanna, 1980). Los antígenos de excreción-secreción fueron reconocidos como importantes en el desarrollo de la formación de anticuerpos en fasciolosis (Sandeman y Howell, 1981) y han sido ampliamente utilizados en el estudio de la fasciolosis animal (Hernández et al., 1996).

El presente estudio constituye un aporte para el diagnóstico individual y poblacional de la fasciolosis en regiones endémicas, usando técnicas inmunológicas basadas en la detección de anticuerpos y coproantígenos. En este trabajo se estandarizó un ensayo inmunoenzimático (ELISA) de detección de anticuerpos y se evaluó un ensayo inmunoenzimático de detección de coproantígenos (sandwich-ELISA) para Fasciola hepatica en un grupo de alpacas.

\section{Material y MéTodos}

\section{Diseño general}

Se estandarizaron y evaluaron dos pruebas diagnósticas para Fasciola hepatica en alpacas: a) El ELISA indirecta para la detección de anticuerpos anti-Fasciola hepatica, utilizando suero de alpacas adultas. En este caso se emplearon los productos de excreción y secreción (ES) como antígenos para el desarrollo de la prueba. Se obtuvo un inmuno conjugado de peroxidasa anti-IgG de alpacas para realizar la lectura de los sueros, determinación del punto de corte, y el cálculo de sensibilidad y especificidad de la prueba de ELISA.

b) El ensayo inmunoenzimático de detección de coproantígeno (ES-78-Sandwich ELISA) fue evaluado utilizando heces de alpacas adultas. Las muestras fecales de estos animales fueron evaluadas mediante el kit de diagnóstico FASCIDIG ${ }^{1}$, el cual detecta antígenos metabólicos del parásito mediante el uso del anticuerpo monoclonal AcM-ES78 de la subclase IgG $2 \mathrm{a}$.

El inmunoconjugado contra IgG de alpaca no se produce comercialmente por lo que tuvo que ser preparado en dos etapas: a) La obtención del inmunosuero y purificación de la anti-IgG de alpacas, y b) La conjugación de la anti-IgG con peroxidasa.

Para la obtención del inmunosuero y purificación de la anti-IgG de alpacas se colectó $44 \mathrm{ml}$ de suero de 10 alpacas coprológicamente negativas a $F$. hepatica y negativas a coproantígenos. El suero fue precipitado al $50 \%$ con solución saturada de sulfato de amonio mediante centrifugación a 3,500 rpm durante $20 \mathrm{~min}$ a $4{ }^{\circ} \mathrm{C}$. Se reconstituyó en $22 \mathrm{ml}$ de solución tampón a base de fosfato de sodio $20 \mathrm{mM}, \mathrm{pH} 6.8, \mathrm{y}$ desalinizado por Filtración en Gel empleando una columna de Sephadex G-25 (10 mm x 30 $\mathrm{cm})$. La IgG fue purificada mediante la combinación de una Cromatografía de Intercambio Iónico (CII) y una Cromatografía de Afinidad (CA). Cada paso cromatográfico rea-

${ }^{I}$ Instituto Parasitológico Pedro Kouri, La Habana-Cuba 
lizado en la purificación de la IgG fue analizado por densitometría y SDS-PAGE.

Para la CII se empleó una columna de Q-Sepharosa Fast Flor $(26 \mathrm{~mm}$ x $10 \mathrm{~cm})$ a una velocidad de flujo de $10 \mathrm{ml} / \mathrm{min}$ empleando como sistema de tampones al fosfato de sodio 20 mM, pH 6.8, en la equilibración y elusión de las moléculas no absorvidas a la matriz y cloruro de sodio $1 \mathrm{M}$ disuelto el fosfato 20 mM, pH 6.8, para la elusión de las moléculas que quedaron retenidas.

En la CA a proteína A, la fracción que quedó retenida en la columna en la que se encontraba la mayor cantidad de IgG fue analizada mediante electroforesis en gel de poliacrilamida (SDS-PAGE), siguiendo el procedimiento descrito por Laemmli (1970). Esta fracción fue, además, concentrada por AMICON y finalmente aplicada sobre una columna XK 16/18 de Proteína A-Sepharosa Fast Flor. Las moléculas que no quedaron retenidas a esta matriz fueron eluídas con SSTF, pH 7.2, a una velocidad de flujo de 2 $\mathrm{ml} / \mathrm{min}$ y las que quedaron específicamente retenidas (IgG de alpaca) fueron eluídas con Glicina $0.1 \mathrm{mM}, \mathrm{pH}$ 3.0. Esta fracción fue inmediatamente colectada y neutralizada a $\mathrm{pH}$ 7.0 con la adición de $20 \mu \mathrm{l}$ de Tris $1 \mathrm{M} \mathrm{pH} 10$. Posteriormente fue desalinizada por Sephadex G-25 y finalmente concentrada por AMICON con membrana YM-100.

\section{Ensayo inmunoenzimático para la detec- ción de anticuerpos contra Fasciola hepatica (ELISA Indirecta)}

Para el análisis y estandarización de la prueba de ELISA para detección de anticuerpos a Fasciola hepatica se consideraron dos grupos de animales:

a) El grupo control positivo, conformado por 12 alpacas procedentes de una zona endémica, donde la crianza era en forma extensiva y mixta (bovinos y ovinos). Los animales presentaron al menos un resultado positivo de tres muestras seriadas con dos semanas de intervalo entre exá- menes al análisis coproparasitológico de F. hepatica.

b) El grupo control negativo, conformado por 28 alpacas procedentes de una zona ubicada sobre los 4,000 msnm, con un sistema de crianza similar, en el cual no se alterna con ovinos ni bovinos. El área de crianza es usualmente seca y los animales son desparasitados bajo un cronograma establecido. Este grupo tuvo tres resultados seriados negativos al examen coproparasitológico para $F$. hepatica (los exámenes se realizaron con un intervalo de 2 semanas entre uno y otro).

Para el desarrollo y estandarización de ELISA indirecto para la detección de anticuerpos anti- $F$. hepatica en alpacas se obtuvieron los siguientes reactivos biológicos:

- Productos de excreción-secreción de Fasciola hepatica

- Obtención de un inmunoconjugado de peroxidasa anti-IgG de alpacas:

a) Obtención del inmunosuero y purificación de la anti-IgG de alpacas

- Cromatografia de intercambio iónico

- Cromatografía de afinidad a proteína A

b) Obtención del suero hiperinmune en conejos

c) Conjugación de la anti-IgG con peroxidasa

- Estandarización del ELISA indirecto:

a) Procedimiento para el ELISA indirecto

b) Punto de corte

\section{Ensayo inmunoenzimático de detección de coproantígeno (ES-78-Sandwich ELISA)}

Para la detección de los antígenos de excreción y secreción (ES) de $F$. hepatica presentes en las heces de las alpacas se empleó un ensayo inmunoenzimático tipo sandwich ELISA que está basado en la detección de los antígenos metabólicos del parásito 
mediante el uso del anticuerpo monoclonal AcM ES78 de la subclase IgG2a.

Para el análisis y estandarización de la prueba de ELISA, se consideraron dos grupos de animales: El grupo control positivo (38 alpacas) y el grupo control negativo (96 alpacas). El origen, manejo y características de estos animales fue similar a lo descrito anteriormente para el ELISA indirecta.

Las muestras de heces de estos animales fueron homogenizadas en agua corriente en proporción de $1 \mathrm{~g} / 2 \mathrm{ml}$. El sobrenadante del homogenizado fue debidamente identificado y congelado a $-20{ }^{\circ} \mathrm{C}$ hasta su análisis por ensayo inmunoenzimático de detección de coproantígenos mediante el Kit de diagnóstico FASCIDIG.

El punto de corte para la prueba de ELISA de coproantígeno se calculó ingresando los valores de densidad óptica (DO) de las muestras de los grupos control positivo y control negativo en una hoja de cálculo, determinando el punto de corte donde la sensibilidad y la especificidad alcanzaron sus mayores valores. Se consideró positiva toda muestra cuyo valor de DO fuese mayor que la DO establecida como punto de corte.

\section{Análisis estadístico}

Cada muestra de suero y heces fue analizada por duplicado, tomándose como valor de absorbancia la media entre ambas determinaciones. Se calculó la especificidad (e), la sensibilidad (s) y los valores predictivos positivo y negativo del ELISA de anticuerpos y el ES78-sandwich ELISA (coproantígeno) empleando una tabla de contingencia de $2 \times 2$.

\section{Resultados}

\section{ELISA Indirecto para la detección de anticuerpos anti-Fasciola hepatica en al- pacas}

Los productos de excreción secreción se obtuvieron mediante la técnica de manteni- miento in vitro. La concentración de proteínas de estos antígenos fue determinada por el método de Lowry, y osciló entre $1.5-2.0 \mathrm{mg} /$ $\mathrm{ml}$.

En las Figs. 1 y 2 se indican los resultados de la cromatografía de intercambio iónico y de afinidad utilizada para la purificación de IgG. En la Fig. 3 se muestran los análisis de pureza realizados a los diferentes pasos de la purificación por electroforesis en gel de poliacrilamida donde se observa que el nivel de pureza para la IgG se va incrementando hasta alcanzar su máxima pureza con la Cromatografía de Afinidad. En la Fig. 4 se indican los resultados de la cromatografía por filtración en gel, observando los tres picos obtenidos, que representan el conjugado (antiIgG de alpaca-peroxidasa), IgG de alpaca (no conjugada) y peroxidasa libre.

La IgG de alpaca purificada fue utilizada para la obtención del suero hiperinmune en conejos. El suero fue titulado por inmunodifusión doble y ELISA, obteniéndose títulos de anticuerpos mayores a 1:64 y de 12,800 , respectivamente.

Al realizar la prueba de ELISA para anticuerpos en los 40 sueros de los grupos control positivo $(\mathrm{n}=12)$ y negativo $(\mathrm{n}=28)$ se obtuvieron valores de densidad óptica que oscilaron en el rango de 0.075 a 1.435 . El punto de corte calculado fue 0.226 , el cual fue determinado cuando la sensibilidad y la especificidad alcanzaron los valores más altos $(100 \%$, respectivamente). Según este criterio, todos los animales con $F$. hepatica (control positivo) resultaron positivos a la prueba de ELISA para anticuerpos con valores de absorbancia que oscilaron en el rango de 0.331 a 1.435 . De igual forma, los animales del grupo control negativo resultaron negativos a la prueba de ELISA con valores de densidad óptica entre 0.075 a 0.226 . Por lo tanto, la sensibilidad, especificidad, valores predictivos positivo y negativo fueron del $100 \%$. 


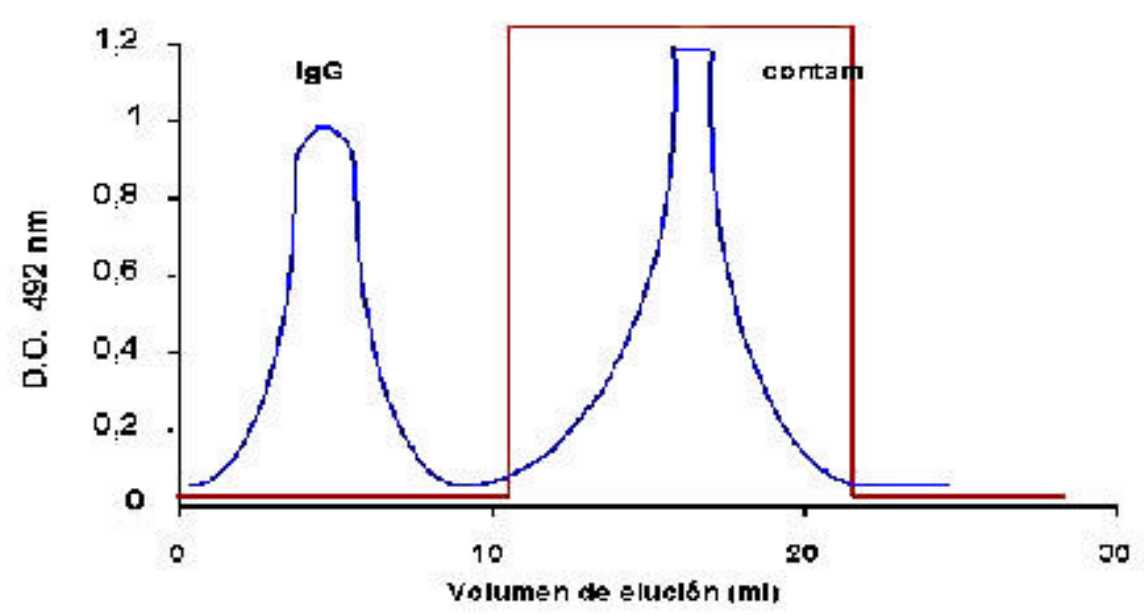

Figura 1. Cromatograma: Purificación de IgG de alpaca por cromatografía de Intercambio lónico (C.I.I.)

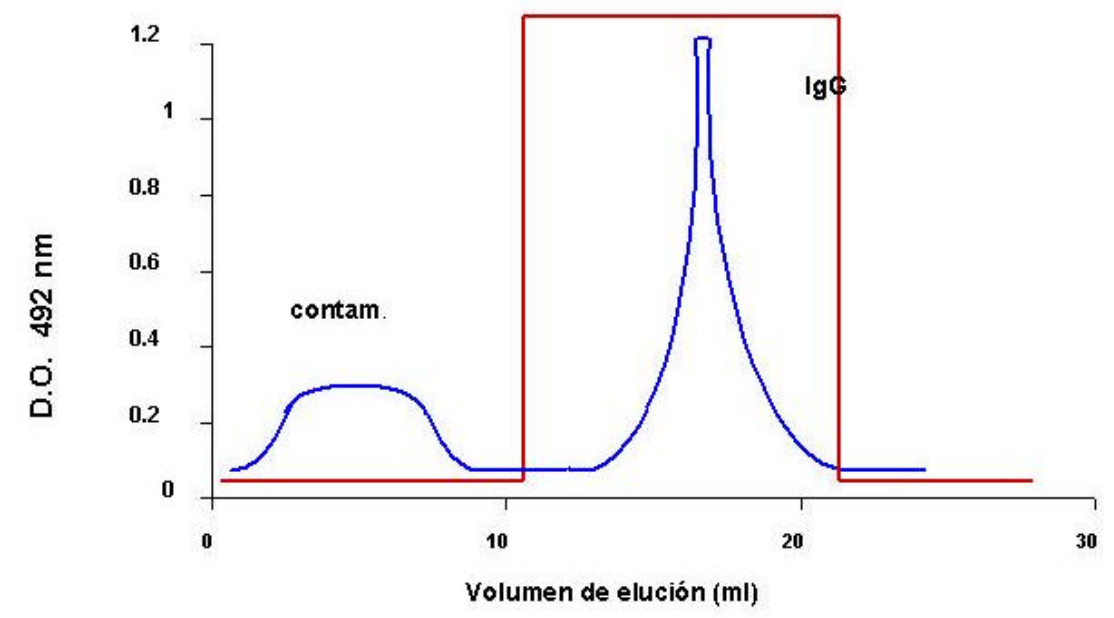

Figura 2. Cromatograma: Purificación de IgG de alpaca por cromatografía de afinidad a proteína $A$

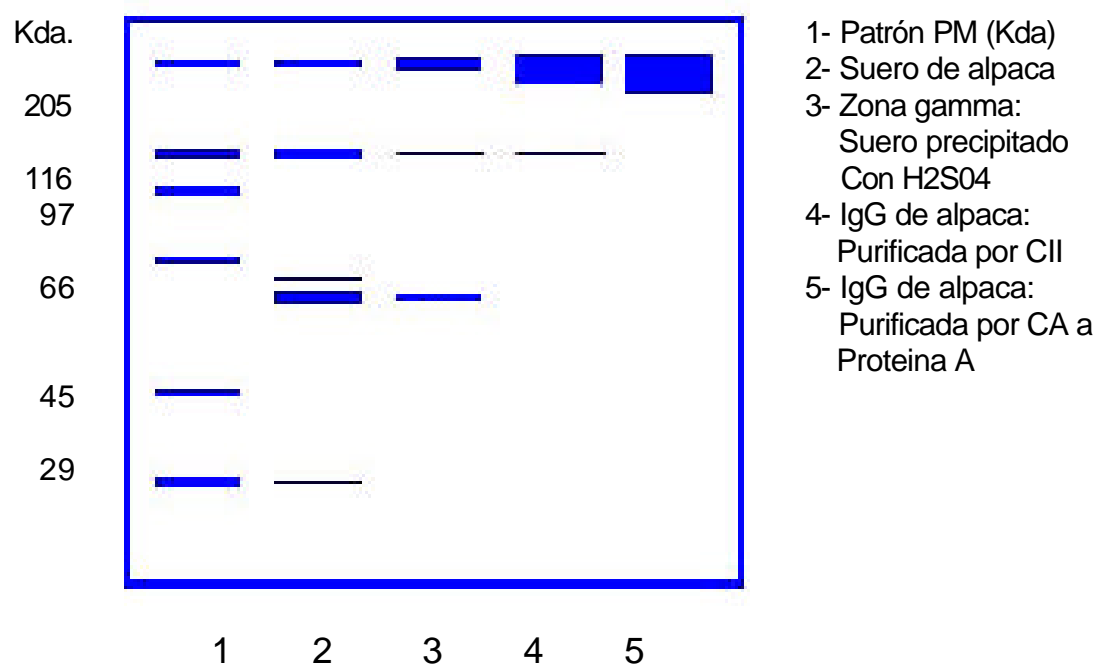

Figura 3. Electroforesis de la purificación de IgG de alpaca (SDS-PAGE) 


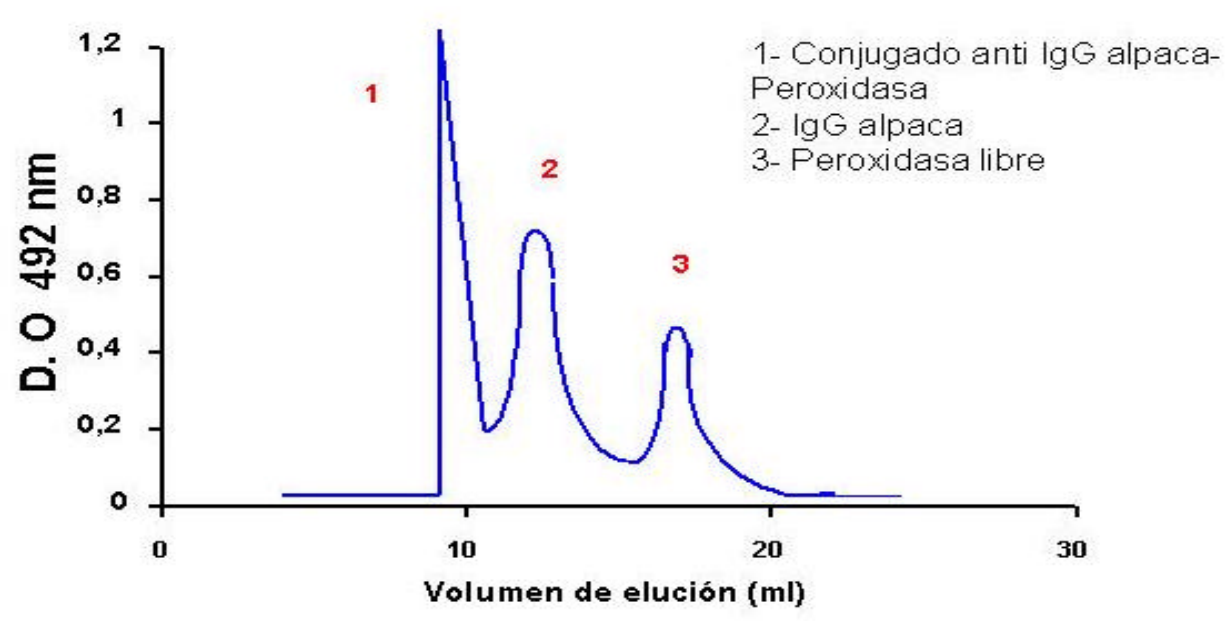

Figura 4. Cromatograma: Purificación del conjugado anti-IgG de alpaca por C.F.G.

\section{Ensayo inmunoenzimático de detección de coproantígeno de Fasciola hepatica (ES-78-Sandwich ELISA)}

Al realizar la evaluación de la prueba de ELISA para la detección de coproantígenos en las 134 suspensiones fecales de alpacas, tanto del grupo control negativo $(\mathrm{n}=96)$ como positivo $(\mathrm{n}=38)$, se obtuvieron valores de $\mathrm{DO}$ que oscilaron en el rango de 0.060 a 1.532 . El punto de corte calculado fue de 0.240 , el cual fue determinado cuando la sensibilidad y especificidad alcanzaron los valores más altos (100\%, respectivamente). Según este criterio, todos los animales con $F$. hepatica (control positivo) resultaron positivos a la prueba de ELISA para coproantígenos con valores de densidad óptica que oscilaron en el rango de 0.244 a 1.532 . Asimismo, los animales del grupo control negativo resultaron negativos a la prueba de ELISA con valores de absorbancia entre 0.060 a 0.240 . Por lo tanto, la sensibilidad, especificidad, y los valores predictivos positivos y negativos fueron del $100 \%$.

\section{Discusión}

Los resultados demuestran que la preparación de un conjugado anti-IgG de alpaca ligado a peroxidasa, es útil para la detección de anticuerpos y, por tanto, para realizar estudios seroepidemiológicos en un gran número de animales pertenecientes a una especie tan poco estudiada.

Los resultados indican que los antígenos de ES de F. hepatica adultos son altamente específicos, ya que, como al ser utilizados en un ensayo inmunoenzimático de detección de anticuerpos, permitieron discriminar totalmente los sueros de pacientes infectados de los no infectados con $F$. hepatica. La diferencia entre estos resultados y los obtenidos por otros investigadores radica en el modo de preparación del antígeno. En este estudio, los productos metabólicos del parásito fueron colectados a las $24 \mathrm{~h}$ de mantenimiento in vitro, durante el cual cada parásito fue cultivado de manera individual; a diferencia de otros trabajos que colectaron los antígenos luego de 7 ó más días de mantenimiento, siendo todos los parásitos cultivados en el mismo frasco.

Como en la técnica de mantenimiento in vitro, los parásitos sobreviven a expensas de sus reservas endógenas, la prolongación del tiempo de mantenimiento suele provocar la muerte a un significativo número de ellos. Los antígenos colectados dentro de las primeras 24 horas son cualitativa y cuantitativamente diferentes. Otros autores que trabajaron posteriormente con antígenos 
de ES de adultos, colectados a sólo 3 horas de mantenimiento, demostraron también la elevada calidad diagnóstica de los mismos (Hillyer y Soler de Galanes, 1991).

Ha sido reportado que una de las vías que utiliza la $F$. hepatica para evadir la respuesta inmune del hospedero es la del recambio antigénico de su superficie tegumentaria (Hanna, 1980), la cual se caracteriza por la presencia de diferentes glándulas secretorias denominadas T0, T1 y T2 que caracterizan al parásito recién desenquistado, inmaduro y adulto, respectivamente, en su migración dentro del hospedero definitivo (Bennet y Threadgold, 1975). Tanto los antígenos de ES de los estadios inmaduros como los del parásito adulto, aunque procedentes de glándulas secretorias funcionalmente diferentes, poseen componentes antigénicos comunes. Es por esta razón que, empleando antígenos de ES de parásitos adultos, se pudo detectar la presencia de anticuerpos en las semanas más tempranas del periodo prepatente, donde éstos debieron ser estimulados por antígenos excretados por las formas inmaduras del parásito.

Espino et al. (1987) observaron que la presencia de anticuerpos contra antígenos de ES pudo ser demostrada en el $100 \%$ de los animales infectados desde periodos muy tempranos de la infección, lo cual corrobora lo reportado por otros autores acerca del importante papel que juegan estos antígenos en la inducción de la respuesta de anticuerpos en la fasciolosis (Sexton et al., 1991).

La mayoría de los métodos de diagnóstico indirecto que aparecen reportados en la literatura están basados en la detección de anticuerpos (Hillyer y Soler de Galanes, 1991). La principal desventaja de cualquier procedimiento diagnóstico basado en este principio, es que la presencia de anticuerpos no es indicativo de infección activa, ya que se ha demostrado que los anticuerpos pueden estar elevados en hospederos que hayan estado expuestos al parásito sin llegar a de- sarrollar la enfermedad y se pueden mantener elevados algún tiempo después de tratados (Espino et al., 1992). Por el contrario, la principal ventaja que presenta el kit diagnóstico FASCIDIG es que se basa en la detección de antígenos de excreción-secreción del parásito vivo y, por lo tanto, es capaz de diagnosticar la infección activa. La especificidad de este kit diagnóstico está dada por la utilización de un anticuerpo monoclonal que sólo reconoce antígenos de excreción-secreción de $F$. hepatica en cualquiera de las etapas de la infección (Espino et al., 1993), ya que al parecer el monoclonal reconoce un epitopo repetitivo en los antígenos de excreción-secreción presentes en las formas inmaduras y maduras del parásito.

Durante su migración por el parénquima, las formas invasivas del parásito excretan una gran cantidad de antígenos que van directamente a la circulación, constituyendo un importante estímulo al sistema inmunológico del huésped, que rápidamente genera la producción de anticuerpos específicos contra estos antígenos.

La coincidencia observada en la dinámica de la antigenemia y los coproantígenos en el modelo humano y el modelo animal indica que durante la infección primaria por $F$. hepatica, la detección de antígenos circulantes sólo tiene valor diagnóstico en las etapas más tempranas de la enfermedad, en tanto que el ensayo de detección de coproantígenos tiene un valor diagnóstico mucho más amplio, pues permite detectar la enfermedad en ambas fases. Los resultados obtenidos en este trabajo con el ensayo de detección de coproantígenos en casos con fasciolosis hepática, se asemejan a los obtenidos por otros autores en estudios de fasciolosis gigantica, los cuales con el uso de anticuerpos policlonales y técnicas de precipitación, pudieron detectar la infección activa en pacientes que se encontraban tanto en la fase aguda como en la fase crónica (Youssef et al., 1991). 
La detección de coproantígenos se hace posible desde que el parásito inmaduro se encuentra próximo a su localización definitiva en el conducto biliar y sus productos metabólicos son vertidos directamente al tracto gastrointestinal. Es evidente que el incremento observado en los niveles de coproantígenos en el modelo experimental y en los pacientes, así como las diferencias altamente significativas encontradas entre la media de los coproantígenos antes y después de la excreción de huevos en ambos modelos, está relacionado con el proceso de desarrollo del parásito en el hospedero, cuyo máximo crecimiento y maduración sexual se alcanza con el inicio de la oviposición (Espino et al., 1997).

El incremento en el número de muestreos por animal aumenta la probabilidad de encontrar más individuos positivos por el examen parasitológico. Teniendo en cuenta que en la fasciolosis el hallazgo de huevos presenta grandes dificultades, en el presente estudio se realizaron tres muestreos parasitológicos con intervalos de 20 días a cada animal, empleando técnicas en las que se examinó minuciosamente todo el contenido fecal. Esto denota claramente que, los exámenes seriados, si bien son eficientes, consumen gran cantidad de tiempo, resultando desventajoso para la realización de estudios epidemiológicos, de brotes epidémicos e incluso para el diagnóstico individual. A diferencia del examen coproparasitológico, el ensayo de detección de coproantígenos pudo detectar desde el primer muestreo el $100 \%$ de animales con fasciolosis. Esto es debido a que la excreción de coproantígenos es constante a diferencia de la excreción de huevos, la cual es intermitente y está ausente en determinados periodos de la enfermedad (Hillyer y Santiago de Weil, 1981).

Los resultados obtenidos en este estudio con el ELISA para la detección de coproantígenos en alpacas han sido muy satisfactorios, con una sensibilidad y especificidad del $100 \%$, lo que es similar a los obtenidos por Espino y Finlay (1994) en humanos de $96 \%$ y $100 \%$, y por Castro (1994) en bovinos con sensibilidad del $99 \%$ y $100 \%$ en rebaños que presentaban alta prevalencia de $F$. hepatica. Estos resultados demuestran que la técnica de detección de coproantígenos en pacientes o animales con fasciolosis, usando el AcM ES-78, es el método de elección para el diagnóstico de infección activa por $F$. hepatica.

El éxito obtenido con la aplicación del ensayo de detección de antígenos se debe en gran medida a la especificidad y capacidad de captura del anticuerpo monoclonal ES78. El hecho de que con el ensayo de detección de antígenos se puede detectar la enfermedad en cualquiera de sus fases indica que el epitopo reactivo para ES78 está localizado sobre moléculas antigénicas excretadas tanto por parásitos inmaduros como por parásitos maduros. Esto puede ser posible, si se tiene en cuenta lo planteado por algunos autores respecto a la existencia de antígenos comunes a los diferentes estadios de desarrollo de $F$. hepatica, de los cuales al menos dos han sido identificados como antígenos de excreción-secreción (Sandeman y Howell, 1981).

La presencia de una molécula de 17 $\mathrm{kDa}$ considerada como un marcador importante de las fases aguda y crónica de la infección (Hillyer y Soler de Galanes, 1988), conlleva a inferir que al menos dos de los componentes identificados por el AcM (24 y $26 \mathrm{kDa})$, por encontrarse dentro del rango de peso molecular o muy próximos a los reportados por estos autores, pudieran ser los componentes antigénicos principales de los antígenos de ES de $F$. hepatica.

\section{Conclusiones}

- El ensayo inmunoenzimático en fase sólida (ELISA indirecta) para detección de anticuerpos en alpacas infectadas con $F$. hepatica demostró ser un método 
sensible y útil para el diagnóstico de fasciolosis pasiva en alpacas.

- El sandwich ELISA para la detección de coproantígenos, utilizando el AcM ES-78, es un método simple, rápido y eficaz en la detección de infección activa por $F$. hepatica en alpacas.

- La sensibilidad, especificidad y valores predictivos del Sandwich ELISA, comparados al examen coproparasitológico, permiten la sustitución de este último, tanto en el diagnóstico individual como en rebaños con infección activa por $F$. hepatica.

- Los métodos diagnósticos para la detección de anticuerpos y de coproantígenos, resultan ser técnicas de elección para estudios seroepidemiológicos y de infección pasiva y activa por $F$. hepatica, respectivamente, en rebaños de gran número de animales sometidos a pastoreo intensivo.

\section{Literatura Citada}

1. Bennett, C.E.; L.T. Threadgold. 1975. Fasciola hepatica: development of tegument during migration in mouse. Exp. Parasitol. 38:38.

2. Castro, J. 1994. Evaluación del estado de infección por Fasciola hepatica en tres unidades pecuarias de ciudad de La Habana utilizando el kit diagnóstico FASCIDIG. Tesis de Maestría. Instituto Parasitológico Pedro Kouri IPK. La Habana, Cuba.

3. Espino, A.M.; B. Duménigo; R. Fernández; C. Finlay. 1987. Inmunodiagnosis of human fascioliasis by enzyme-linked immunosorbent assay using excretory secretory products. Am. J. Trop. Med. Hyg. 37: 605-608.

4. Espino, A.M.; L. Millán; C. Finlay. 1992. Detection of antibodies and circulating excretory-secretory antigens for assesing cure of patientes with fascioliasis. Trans. Roy. Soc. Trop. Med. Hyg. 86: 649.
5. Espino, A.M.; N. Seuret; L. Escobar; B.E. Duménigo. 1993. Identificación y aislamiento de antígenos comunes de Fasciola hepatica. Rev. Cub. Med. Trop. 45: 20-26.

6. Espino, A.M.; R. Marcet; C.M. Finlay. 1997. Fasciola hepatica: detection of antigenemia and coproantigens in experimentally infected rats. Exp. Parasitol. 85: 117-120.

7. Espino, A.M.; C.M. Finlay. 1994. Sandwich enzime-linked immunosorbent assay for detection of excretorysecretory antigens in humans with fascioliasis. Clin. Microbiol. 32 : 190-193.

8. Hanna, R.E.B. 1980. Fasciola hepatica: an immunofluorescent study of antigenic changes in the tegument during development in the rat and the sheep. Exp. Parasitol. 50:155-159.

9. Hernández, H.M.;B.E. Duménigo; A.M. Espino; R. Marcet; C.M. Finlay. 1996. Detección de anticuerpos contra antígenos de excreción secreción de Fasciola hepatica en bovinos infectados empleando un ensayo inmunoenzimático sobre fase sólida. Rev. Cub. Med. Vet. 47: 56-60.

10. Hillyer, G.V.; M. Soler de Galanes. 1991. Initial feasibility studies of the FAST-ELISA for the immunodiagnosis of fascioliasis. Parasitol. 77: 362-365.

11. Hillyer, G.V.; M. Soler de Galanes. 1988. Identification of a 17-Kilodalton Fasciola hepatica immunodiagnostic antigen by the enzyme-linked immunoelectrotransfer blot technique. J. Clin. Microb. 26: 2048-2053.

12. Hillyer, G.V.; M. Soler de Galanes; J.B. Rodríguez-Pérez; M.S. De Lagrava; S. Ramírez-Guzmán; R.T. Bryan. 1992. Use of the Falcon assay screening test-enzyme-linked immunosorbent assay (FAST ELISA) and the enzyme-linked immunotransfer blot (EITB) to determine the prevalence of human fascioliasis in the Bolivian Altiplano. Am. J. Trop. Med. Hyg. 46: 603-609. 
13. Hillyer, G.V.; N. Santiago de Weil. 1981. Serodiagnosis of experimental fascioliasis by immunoprecipitation test. Internat. J. Parasitol. 11: 71-78.

14. Langley, R.J.; G.V. Hillyer. 1989. Detection of circulating parasite antigens in murine fascioliasis by two-site enzyme linked immunosorbent assay. Am. J. Trop. Med. Hyg. 41: 472-478.

15. Lehner, R.P.; M.M.H. Sewell. 1980. A study of the antigens produced by adult Fasciola hepatica maintenance in vitro. Parasite Immunol. 2: 99-109.

16. Ministerio de Salud Pública. 1991/ 1995. Cuadro Epidemiológico Nacional. Ciudad de La Habana, Cuba. 195 p.
17. Sandeman, R.M.; M.J. Howell. 1981.

Precipitating antibodies against excretory secretory antigens of Fasciola hepatica in sheep serum. Vet. Parasitol. 9: 35-46.

18.Sexton, J.L.; A.R. Milner; N.I. Campbell. 1991. Fasciola hepatica immuno-precipitation analysis of biosynthetically labelled antigens using sera from infected sheep. Parasite Immunol. 13: 105108.

19. Youssef, R.G.; N.S. Mansour; A.G. Azis. 1991. Early diagnosis of human fascioliasis by the detection of coproantigens using counterimmunoelectrophoresis. Trans. Royal Soc. Trop. Med. Hyg. 85: 383-384. 